\title{
O PLANO EDUCACIONAL INDIVIDUALIZADO: \\ PROPOSTA DE UM MÉTOdO DE PESQUISA NA FORMAÇÃO DOCENTE
}

\begin{abstract}
THE INDIVIDUALIZED EDUCATIONAL PLAN:
PROPOSAL OF A RESEARCH METHOD IN TEACHER TRAINING

EL PLAN EDUCACIONAL INDIVIDUALIZADO:

PROPUESTA DE UN MÉTODO DE INVESTIGACIÓN EN LA FORMACIÓN DOCENTE

\author{
Letícia Aparecida Alves de Lima ${ }^{1}$ \\ Ana Eliza Gonçalves Ferreira ${ }^{2}$ \\ Marcus Vinicius Gonçalves da Silva ${ }^{3}$
}

RESUMO: O objetivo deste estudo é propor um metódo de pesquisa para a elaboração do Plano Educacional Individualizado (PEI) no âmbito das escolas públicas brasileiras. O procedimento metodológico classifica-se quanto à finalidade, em pesquisa básica; com relação ao problema de pesquisa, tem abordagem qualitativa; quanto aos objetivos, a pesquisa é exploratória e descritiva. Os resultados revelam que há uma incipiência na literatura relacionada à produção de conhecimento sobre o PEI e, que a partir da metodologia de pesquisa-ação colaborativa entre o pesquisador acadêmico, os professores regulares e a equipe do Atendimento Educacional Especializado nas escolas públicas, o PEI seja um instrumento efetivo ao introduzir práticas pedagógicas auxiliadoras na rotina de ensino.
\end{abstract}

PALAVRAS-ChAVE: Formação docente. Metodologia. Plano educacional individualizado.

ABSTRACT: The objective of this study is to propose an academic research method for the elaboration of the Individualized Educational Plan (IEP), PEI, in Brazil, in the scope of the Brazilian public schools. The methodological procedure is classified for the purpose, in basic research; with respect to the research problem, has a qualitative approach; objectives, the research is exploratory and descriptive. The results show that there is an incipience in the literature related to the production of knowledge about the IEP and, that from the collaborative research-action methodology between the academic researcher, the regular teachers and the staff of the Specialized Educational Assistance in the public schools, the IEP is an effective instrument in introducing pedagogical practices that aid the teaching routine.

KEYWORDS: Teacher training. Methodology. Individualized educational plan.

RESUMÉN: El objetivo de este estudio es proponer un metódulo de investigación para la elaboración del Plan Educativo Individualizado (PEI) en el ámbito de las escuelas públicas brasileñas. El procedimiento metodológico se clasifica en cuanto a la finalidad, en investigación básica; con respecto al problema de investigación, tiene abordaje cualitativo; en cuanto a los objetivos, la investigación es exploratoria y descriptiva. Los resultados revelan que hay una incipiente en la literatura relacionada a la producción de conocimiento sobre el PEI y que a partir de la metodología de investigación-acción colaborativa entre el investigador académico, los profesores regulares y el equipo del Servicio Educativo Especializado en las escuelas públicas, el PEI sea un instrumento efectivo al introducir prácticas pedagógicas auxiliares en la rutina de enseñanza.

PALABRAS CLAVE: Formación docente. Metodología. Plan educativo individualizado.

Submetido em: 08/12/2017 - Aceito em: 05/02/2018 - Publicado em: 27/03/2018.

\begin{tabular}{l|c|c|c|c|c|c} 
(C) Rev. Educ. Perspec. & Viçosa, $M G$ & v.9 & n.1 & p.127-141 & jan./abr. 2018 & eISSN 2178-8359 \\
\hline
\end{tabular}




\section{INTRODUÇÃO}

Hodiernamente, a educação de crianças e jovens com necessidades educacionais especiais no Brasil se define por um sistema dual em que de um lado existe um forte sistema caracterizado pelo assistencialismo filantrópico custeado de forma difusa por várias instâncias do poder público, e de outro, um sistema educacional fragilizado que vem sendo impelido a abrir espaço para a educação escolar desta parcela da população (MENDES, 2010).

A discussão sobre como deve ser a escolarização de alunos com necessidades especiais não é um tema novo, porém, atualmente, tenta-se pensar no assunto como uma possibilidade de fato e não como algo que deva ser encoberto e marginalizado por meio de práticas descontínuas e segregadas (MAZZOTTA, 2005).

No entanto, para redimensionar tais práticas, a fim de que estas promovam o desenvolvimento social e acadêmico desse alunado, sem cair-se no risco da exclusão intraescolar, precisa-se fomentar uma reflexão sobre o currículo, ainda marcado por ser uma estrutura com características de rigidez, descontextualizada e sem significado (PLETSCH, 2010).

Nesse sentido, Young (2014, p. 195) revela que "se o currículo for definido apenas por resultados e competências, ele será incapaz de prover acesso ao conhecimento". Desse modo, observa-se a conveniência de efetivar distintas possibilidades para que as necessidades de aprendizagem desses alunos sejam consideradas na implementação do currículo, bem como, em sua realização nas diferentes atividades que os docentes desenvolvem com eles, visando sua inserção social e escolar pela via do conhecimento.

Nesse viés, ressalta-se a importante contribuição do Plano Educacional Individualizado (PEI) em consonância com o disposto na Resolução $n^{\circ}$ 4, em seu artigo $9^{\circ}$ (BRASIL, 2009), que aponta para a necessidade de realização de um trabalho em colaboração entre professores do ensino regular e do Atendimento Educacional Especializado (AEE), contribuindo para o desenvolvimento desse aluno, conforme também se verifica no inciso VII do Art. 13

VII - estabelecer articulação com os professores da sala de aula comum, visando à disponibilização dos serviços, dos recursos pedagógicos e de acessibilidade e das estratégias que promovem a participação dos alunos nas atividades escolares (BRASIL, 2009, Art. 13).

Logo, se faz necessário que tais estratégias estejam pautadas num diálogo crítico entre o currículo e as práticas pedagógicas ofertadas aos alunos com deficiência, além da confirmação da participação efetiva de todos os envolvidos no processo de escolarização dos mesmos.

\begin{tabular}{l|c|c|c|c|c|c|}
\hline () Rev. Educ. Perspec. & Viçosa, $M G$ & v.9 & n.1 & p.127-141 & jan./abr. 2018 & eISSN 2178-8359 \\
\hline
\end{tabular}


Nessa perspectiva, o PEI vem sendo apresentado no Brasil como uma importante estratégia para elaborar, implementar e avaliar adaptações curriculares que favoreçam a inserção de alunos com necessidades educacionais especiais em turmas regulares de ensino, norteando as ações pedagógicas dos professores (VIANNA et al., 2011).

Há, portanto, a necessidade de se promover nas escolas que atendam alunos com necessidades educacionais especiais, ações continuadas e colaborativas, ancoradas no diálogo entre os conhecimentos produzidos nas universidades e o saber docente construído no cotidiano das práticas escolares.

O pressuposto inicial é de que pensar em um currículo individualizado encontra relação com o rompimento de paradigmas existentes, posto que, o plano que será traçado para o aluno, não necessariamente seguirá o conteúdo completo do ano em que está matriculado, podendo ser baseado em metas específicas, por meio de um programa criado de forma personalizada para atender suas necessidades. Outro pressuposto é de que o PEI se efetivará com o envolvimento dos profissionais da área, e não somente pela via das políticas educacionais instituídas.

Diante desse contexto introdutório, propõe-se nesse estudo uma metodologia para a elaboração do Plano Educacional Individualizado para os alunos com necessidades especiais nas escolas da rede pública.

Para atingir este objetivo, este estudo está estruturado em seis seções. A primeira inclui a presente introdução, na qual se apresenta o tema, o objetivo e os pressupostos. A segunda, terceira e quarta seção são destinadas ao suporte teórico, em que são abordados os conceitos, fundamentos e características da avaliação pedagógica na educação inclusiva; a formação docente e a avaliação curricular; e, o plano educacional individualizado. Na quinta seção, em atendimento ao objetivo do estudo, apresenta-se uma proposta metodológica para a elaboração do PEI no âmbito das escolas públicas. Por fim, a sexta seção é dedicada às considerações finais e sugestões para os trabalhos futuros.

\section{A AVALIAÇÃo PEDAGÓGICA NA EDUCAÇÃO INCLUSIVA}

No Brasil, o governo federal determinou à rede pública de ensino de todos os entes federativos que incorporassem a proposta inclusiva, tornando obrigatória, dentre outros aspectos, a matrícula escolar de alunos com necessidades especiais físicas, sensoriais, mentais e psicológicas e os avaliados com altas habilidades/superdotação no sistema regular comum de aprendizagem (BRASIL, 2008; 2008b). 
Nessa vertente, de acordo com a Declaração de Salamanca (1994), as escolas regulares com orientação inclusiva constituem os meios mais eficazes de combater atitudes discriminatórias, e que alunos com necessidades educacionais especiais devem ter acesso à escola regular, tendo como princípio orientador que "as escolas deveriam acomodar todas as crianças independentemente de suas condições físicas, intelectuais, sociais, emocionais, linguísticas ou outras" (DECLARAÇÃO DE SALAMANCA, 1994, s. p.).

De outro modo, as Diretrizes da Educação Especial na Educação Básica indicam que "em vez de pressupor que o aluno deva ajustar-se a padrões de "normalidade" para aprender, aponta para a escola o desafio de ajustar-se para atender a diversidade de seus alunos" (BRASIL, 2001, p. 33, grifo do autor), o que leva a escola a estabelecer diversas adaptações, sejam elas curriculares, estruturais, pedagógicas, de materiais didáticos, recursos humanos etc.

Assim, a avaliação pedagógica dos alunos que apresentarem necessidades educacionais especiais deverá levar em consideração as variáveis que incidam na aprendizagem; as de cunho individual; as que incidam no ensino, como as condições da escola e prática docente; e, as que inspiram diretrizes gerais da educação e as relações que se estabelecem entre todas elas.

Entretanto, Pletsch e Glat (2012) afirmam que mais do que reestruturar práticas pedagógicas e propor ajustes curriculares, é necessário disponibilizar conhecimentos teórico-práticos e suporte aos profissionais da educação para que possam realizar mediações pedagógicas que favoreçam o processo de ensino e aprendizagem de todos os alunos, sobretudo daqueles que apresentam necessidades educacionais especiais.

Martín e Solé (2011) compartilham dessa concepção e acrescentam que a avaliação deve proporcionar uma visão direcionada às potencialidades e dificuldades do aluno, assim como promover respostas educativas mais ajustadas às necessidades, a partir do conhecimento das características das práticas instrucionais com as quais está envolvido.

Diante do exposto, ao se prever a participação de diferentes atores na elaboração do PEI, percebe-se ainda no ambiente escolar a falta de conhecimento e a precária formação dos docentes para atuar na inclusão e escolarização do aluno com deficiência.

A assertiva acima é corroborada por Vianna et al. (2011), ao verificarem que tanto as escolas especializadas quanto as regulares não estão habituadas com o PEI. Do mesmo modo, em estudo realizado sobre o PEI como estratégia para o desenvolvimento acadêmico de alunos com deficiência, Glat e Pletsh (2013) afirmam que a ferramenta é uma prática ainda pouco aplicada.

\begin{tabular}{l|c|c|c|c|c|c|}
\hline () Rev. Educ. Perspec. & Viçosa, $M G$ & v.9 & n.1 & p.127-141 & jan./abr. 2018 & eISSN 2178-8359 \\
\hline
\end{tabular}




\section{BREVE CONTEXTO DA PRÁTICA DOCENTE NA EDUCAÇÃO ESPECIAL}

Lovisolo (1995) ao discorrer sobre a relação entre sustentação acadêmica e intervenção de professores, sugere que um elevado número de docentes realiza uma intervenção profissional fragmentária, assistemática e, não gradativa, ainda ressentida da utilização de recursos diversos em função de objetivos sociais.

Nesse aspecto, a formação continuada se apresenta como uma possibilidade de outros modos de formação docente, em que todos os atores têm papéis estratégicos, em que os saberes da experiência se conjugam com as questões conceituais e teóricas, formando um corpo de aprendizagens docentes que interfere tanto na prática escolar como na elaboração de pressupostos teóricos (VIANNA et al., 2011).

Assim, a "melhoria da qualidade de ensino pode começar, inclusive, pela reflexão da própria prática, ou seja, o reconhecimento de que o processo de aprender a ensinar se prolonga durante toda a carreira do professor" (ZEICHNER, 1993, p. 17).

Na mesma vertente, Therrien (1993, p. 411) aponta que "o saber de experiência como elemento de prática docente é a expressão de um saber social próprio produzido numa práxis cotidiana".

Do mesmo modo, Tartuci et al. (2014) apontam que as trocas de experiências e conhecimentos entre os professores, a aproximação da universidade-escola, pesquisa-ensino e formação inicial-formação continuada constituem como elementos essenciais para que alunos com deficiência tenham acesso, permanência e sucesso nas escolas regulares.

\section{O PLANO EDUCACIONAL INDIVIDUALIZADO}

Como a exclusão acontece dentro do âmbito educacional, observa-se que não são as leis que garantirão o efetivo processo de escolarização e socialização dos alunos, mas sim as práticas pedagógicas inclusivas.

Conforme descrevem Kempinski et al. (2015), um aspecto que chama a atenção nessa basilar ressignificação das instituições de ensino com vistas à efetivação de práticas pedagógicas alinhadas às políticas educacionais inclusivas, se refere a elaboração e utilização do plano educacional individualizado.

A despeito da presença na literatura pertinente, o Plano Educacional Individualizado, ou Programa de Educação Individualizado (GALLAHUE; DONNELLY, 2008) tem tido pouca

\begin{tabular}{l|c|c|c|c|c|c} 
(C) Rev. Educ. Perspec. & Viçosa, $M G$ & v.9 & n.1 & p.127-141 & jan./abr. 2018 & eISSN 2178-8359 \\
\hline
\end{tabular}


visibilidade nos debates relacionados à escolarização de pessoas com necessidades especiais, sobremaneira no conteúdo empírico desses debates (PORTUGAL, 2006; PACHECO et al., 2007; SMITH, 2008).

Observa-se que embora esse instrumento tenha múltiplas denominações, sua característica comum é que se constitui um registro avaliativo escrito, formulado em equipe, que busca as respostas educativas mais adequadas para as necessidades específicas em processos de escolarização de estudantes que demandam caminhos diversos para sua aprendizagem.

No estudo de Glat et al. (2012), as autoras apontam que o instrumento foi concebido nos moldes dos planos individuais de inclusão há muito utilizados nas redes escolares de países da Europa e dos Estados Unidos (PACHECO et al., 2007; PORTUGAL, 2008), com o escopo de se promover o desenvolvimento e a futura inserção social e laboral de alunos com deficiências.

Porém, Munster et al. (2014) observam que diferente do que geralmente acontece nos Estados Unidos, as escolas brasileiras não dispõem da sistematização de informações incluídas no PEI relacionada ao atendimento das necessidades especiais.

Sugere-se que a partir de um planejamento educacional individualizado, seja possível estimular a formulação de estratégias pedagógicas específicas a serem empregadas no desenvolvimento de alunos com deficiência nas áreas acadêmicas e de habilidades sociais, dependendo da faixa etária, do nível de desenvolvimento e/ou interesse do sujeito.

Preliminarmente, foi possível identificar na literatura, que o PEI pode ser um instrumento que não só favorece processos inclusivos no ambiente escolar, mas também contribui para a promoção desses processos, de maneira que qualquer pessoa que apresente características peculiares de aprendizado, estando em uma escola regular ou especializada, poderá utilizá-lo.

Nesse ponto, consiste o desafio da escola identificado por Vygotski (1997), isto é, a proposição de atividades direcionadas que modifiquem qualitativamente a vida desses sujeitos, privilegiando o processo e não o produto final. Também presente na argumentação legal e nas práticas educacionais, o conceito de adaptação curricular está distante da mera ideia de "arranjo" nas atividades, pois conforme revela Souza (2014), a adaptação envolve rever o currículo, o conteúdo e a avaliação, e não somente elementos técnicos.

Portanto, o PEI caracteriza-se como uma ferramenta conveniente para auxiliar a prática pedagógica por meio de planejamentos e avaliações contínuas, ou seja, sua estruturação envolverá tanto adaptações curriculares específicas quanto inserção ao trabalho geral proposto para a turma (PACHECO et al., 2007).

\begin{tabular}{l|c|c|c|c|c|c} 
() Rev. Educ. Perspec. & Viçosa, $M G$ & v.9 & n.1 & p.127-141 & jan./abr. 2018 & eISSN 2178-8359 \\
\hline
\end{tabular}


Nessa senda, o Decreto n $^{0}$ 7.611, de 17 de novembro de 2011, que dispõe sobre a Educação Especial e o Atendimento Educacional Especializado, no seu artigo $1^{\circ}$, aponta a ideia de individualização quando apresenta entre as suas diretrizes:

\begin{abstract}
garantia de ensino fundamental gratuito e compulsório, asseguradas adaptações razoáveis de acordo com as necessidades individuais; adoção de medidas de apoio individualizadas e efetivas, em ambientes que maximizem o desenvolvimento acadêmico e social, de acordo com a meta de inclusão plena (BRASIL, 2011, grifo nosso).
\end{abstract}

A partir do entendimento do desempenho do indivíduo, conforme registra Martini (2016), a avaliação psicoeducacional não visa diagnosticar, segregar, rotular ou estigmatizar os alunos, mas sim proporcionar uma intervenção de modo mais eficaz.

\title{
Proposta do Método
}

A partir da observação realizada na Seção de Atendimento Educacional Especializado (SAEE) em uma escola da rede pública federal, verifica-se a necessidade de se discutir sobre os conceitos, concepções e interações da adaptação curricular e do PEI, principalmente pelo fato de que esta ferramenta educacional é ainda desconhecida, sendo uma oportunidade de pesquisa relevante e inédita na área da educação (KEMPINSKI et al., 2015).

Por se tratar de uma estratégia de ensino aplicada, a construção do PEI deve ser concretizada no âmbito escolar a partir da vivência e dos conhecimentos dos atores envolvidos diretamente com os processos de ensino e aprendizagem. Sugere-se então, que a investigação ocorra a partir de uma matriz qualitativa e descritiva, utilizando-se da metodologia de "pesquisa-ação colaborativa", em que o pesquisador se ocupa ao mesmo tempo da ação e da investigação com a construção e revisão dos procedimentos de acordo com o desenvolvimento do trabalho (THIOLLENT, 1988).

Nessa reflexão, Braun (2004 apud PLETSCH; GLAT, 2010, p. 4) afirmam que a pesquisaação se apresenta com as seguintes características:

\footnotetext{
c) é democrática, na medida em que possibilita aos participantes se envolverem com a pesquisa, influenciando-a e relacionando-a com as ações das suas vivências diárias; d) é interpretativa, uma vez que todas as perspectivas e opiniões dos participantes têm legitimidade, em vez de serem as opiniões do pesquisador as únicas consideradas; e) finalmente, é crítica, pois envolve todos os participantes numa posição reflexiva diante das ações a serem tomadas, ou analisadas, para possíveis mudanças que possam vir a desenvolver.
}

A partir do diálogo entre o conhecimento teórico estudado e produzido na universidade e as reflexões e ações dos professores da instituição participante, vislumbra-se a constituição de novos conhecimentos e saberes que poderão qualificar tanto o trabalho docente na escola básica quanto o trabalho de pesquisa no âmbito acadêmico.

\begin{tabular}{l|c|c|c|c|c|c|} 
(C) Rev. Educ. Perspec. & Viçosa, $M G$ & v.9 & n.1 & p.127-141 & jan./abr. 2018 & eISSN 2178-8359 \\
\hline
\end{tabular}


Desse modo, a metodologia implicará em uma ampla interação, o que possibilitará condições dialógicas permanentes, conjugando contribuições de cada um dos atores (pesquisador, participantes e docentes), promovendo a elaboração coletiva de soluções para as questões apresentadas e a revisão das ações, quando a avaliação contínua indicar a necessidade de modificações.

\section{Participantes da pesquisa}

$\mathrm{Na}$ elaboração do PEI, aponta-se para a importância de que os participantes sejam os docentes do ensino regular da educação básica; os integrantes da equipe da Seção de Atendimento Educacional Especializado (SAEE); e, os alunos com necessidades especiais da escola pesquisada, pois como lembra Nascimento (2011), as necessidades individuais do aluno, constituem a base para a elaboração do plano, que deve indicar priorização de tarefas e modos de avaliação que possibilitem o atendimento a estas necessidades.

Para Jesus (2006), desenvolver uma pesquisa com professores é torná-los sujeitos do processo de pesquisa, pois assim eles se tornam sujeitos participantes a partir do momento que trazem as informações para o campo da pesquisa e realizam a ação-reflexão-ação dos participantes da mesma.

Nesse ínterim, Glat e Pletsch (2013) sugerem que a avaliação pode ser realizada por meio de diferentes instrumentos, dentre eles, a observação direta, entrevistas com professores, profissionais de apoio, familiares e o próprio aluno.

\section{Coleta dos dados}

A coleta de dados, de cunho colaborativo, poderá ocorrer a partir de debates em grupos acerca de um tema ou tópico específico cujo direcionamento da discussão poderá ser mediado pelo chefe da SAEE ou um pedagogo da escola.

Nessa perspectiva, a produção de conhecimentos se dará por meio da valorização da prática e a partir de ações e de reflexões coletivas, pressupondo uma ampla interação entre sujeito e pesquisador, oferecendo um diálogo permanente que seja capaz de acrescentar as contribuições dos sujeitos, elaborando soluções para os desafios apresentados.

De tal modo, a utilização de procedimentos como o registro em diário de campo; a análise documental, por meio de documentos oficiais e os fornecidos pela escola; entrevistas semiestruturadas com os docentes que atuam no atendimento educacional especializado; e, a participação dos alunos a fim de se avaliar e validar o PEI poderá contribuir de forma significativa para a elaboração desse instrumento.

\begin{tabular}{l|c|c|c|c|c|c|}
\hline () Rev. Educ. Perspec. & Viçosa, $M G$ & v.9 & n.1 & p.127-141 & jan./abr. 2018 & eISSN 2178-8359 \\
\hline
\end{tabular}


Sugere-se, que após a coleta dos dados, a equipe de pesquisadores e professores analise os questionários preenchidos a fim de selecionar os alunos para a elaboração do PEI. Alguns critérios de seleção podem ser adotados como: a limitação do número de alunos em pequenos grupos, possibilitando uma melhor assistência por parte dos pesquisadores; heterogeneização da faixa etária, tendo alunos de todos os ciclos de desenvolvimento; e, verificação das demandas mais relevantes em relação às habilidades sociais e acadêmicas dos alunos, de forma a estabelecer metas e prazos a serem alcançados.

A elaboração dessas metas deverá ser temporal, ou seja, delimitará o escopo do tempo para sua realização. A consecução das metas e seus indicadores de curto e longo prazo facilitará o acompanhamento dos alunos, de forma que os planos sejam avaliados pelo menos a cada semestre no ano ou de acordo com a necessidade dos alunos.

\section{Etapas}

Propõe-se na elaboração do PEI, a sequência das etapas propostas por Correia (1997) citadas por Cruz et al. (2011), quais sejam:

i) Identificação, ou seja, a "avaliação preliminar para a identificação do aluno com necessidades específicas, considerando as possíveis adaptações curriculares e mudanças ambientais" (CRUZ et al., 2011, p. 4, grifo dos autores). Nesta etapa, sugere-se a realização de uma entrevista pelos docentes, com a finalidade de se identificar o nível atual de desempenho do aluno, ou seja, suas habilidades. Essas habilidades poderão ser levantadas com o preenchimento de um roteiro de observação.

ii) Avaliação, que busca determinar as necessidades educacionais do aluno, considerando suas potencialidades e limitações. No preenchimento do roteiro de observação de habilidades, o professor poderá identificar o desempenho do aluno em categorias como comunicação oral, leitura, escrita e raciocínio lógico. Consubstanciado pelo roteiro de observação, o professor passará a fase de avaliação do aluno e as necessidades a serem consideradas.

iii) Implementação: nesta etapa, após o preenchimento do roteiro de observação, será possível a construção do Plano Educacional Individualizado. No planejamento, conforme as características individuais identificadas, os docentes passarão a elaborar os conteúdos a serem trabalhados com os educandos, as estratégias e os materiais a serem utilizados, na promoção do desenvolvimento dos alunos com necessidades especiais.

O fluxograma das ações que sintetizam essas etapas pode ser observado na Figura 1.

\begin{tabular}{l|c|c|c|c|c|c|}
\hline (C) Rev. Educ. Perspec. & Viçosa, $M G$ & v.9 & n.1 & p.127-141 & jan./abr. 2018 & eISSN 2178-8359 \\
\hline
\end{tabular}




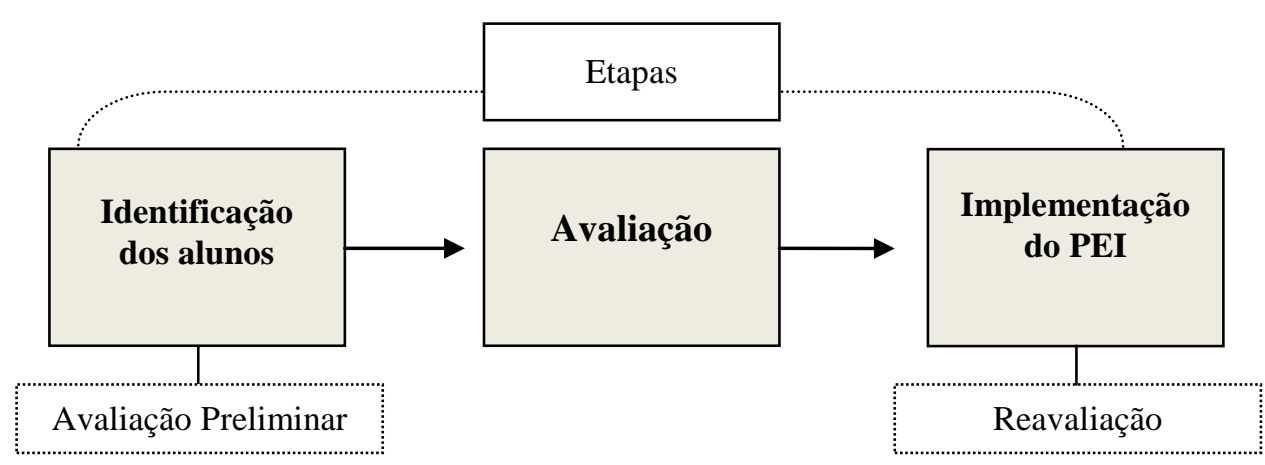

Figura 1. Fluxograma das etapas de elaboração do PEI

Fonte: Elaborado pelos autores

Nota-se que durante o ciclo dessas etapas, poderá ocorrer a necessidade de a escola se reestruturar, a fim de oferecer o suporte necessário, como, por exemplo, a adaptação dos materiais e recursos pedagógicos de acordo com as necessidades específicas de cada aluno, de modo a proporcionar uma (re)avaliação do nível de desempenho acadêmico e funcional do mesmo.

Essas etapas visam clarificar os professores quanto à elaboração de estratégias pedagógicas individualizadas a serem empregadas, ao mesmo tempo em que se propõe mitigar as dificuldades dos docentes em descrever as aprendizagens relativas ao currículo escolar.

Portanto, o PEI se identifica como um instrumento capaz de mobilizar as informações inerentes ao aluno sob a perspectiva de suas habilidades presentes e/ou necessárias, servindo de um método de reflexão e análise para o planejamento e acompanhamento dos alunos durante o ano letivo.

\section{CONSIDERAÇÕES FINAIS}

Ao retomar a proposta deste artigo, reitera-se a percepção de que a elaboração e aplicação do PEI pode ser uma estratégia efetiva para nortear a organização curricular no sentido de impulsionar o desenvolvimento social e acadêmico de alunos das escolas públicas com necessidades especiais, bem como, apoiar suas perspectivas de inclusão escolar e laboral.

Com a metodologia de pesquisa-ação proposta neste estudo, espera-se que o PEI, ao ser elaborado de forma colaborativa entre pesquisadores, professores regulares e a equipe do AEE das escolas públicas seja um instrumento efetivo ao introduzir práticas pedagógicas auxiliadoras na rotina de ensino.

\begin{tabular}{l|c|c|c|c|c|c} 
(C) Rev. Educ. Perspec. & Viçosa, $M G$ & v.9 & n.1 & p.127-141 & jan./abr. 2018 & eISSN 2178-8359 \\
\hline
\end{tabular}


Quanto aos docentes, espera-se que o método seja caracterizado por uma intensa interação e diálogo, pois a escola é o locus apropriado para a formação continuada, considerando que a experiência e o cotidiano escolar possibilitam que os professores possam aperfeiçoar sua formação.

Ainda nessa perspectiva, tal proposta vai ao encontro da dificuldade ora identificada na literatura pelos docentes, em relação à escolarização das pessoas com deficiência, contribuindo assim para uma mudança na prática pedagógica.

Reafirma-se então a ideia de que na busca de caminhos para auxiliar os alunos com particularidades de aprendizado, o PEI mostra-se como uma importante ferramenta para refinar este processo, guiando de forma conjunta a formação continuada dos professores, visando o aperfeiçoamento de procedimentos educacionais como avaliação, planejamento e acompanhamento das atividades escolares desenvolvidas, promovendo a aprendizagem a todos os alunos, independente de suas dificuldades e diferenças.

Uma das formas de nivelar essas diferenças é realizar a construção do PEI com a finalidade de garantir congruência e aprofundamento no trabalho pedagógico, permitindo assim, avanços necessários e oportunos ao desenvolvimento de cada aluno, direcionando o trabalho do educador.

Seguramente, há necessidade de se ampliar os estudos do PEI, com a finalidade de validar sua utilização. Sugere-se então, para investigações futuras, o aperfeiçoamento do método proposto neste estudo por pesquisadores da área da educação e docentes das escolas públicas, com a publicização dos achados teórico-práticos, a fim de se incrementar a produção do conhecimento sobre o PEI e a avaliação do alunado com necessidades educacionais especiais.

\section{REFERÊNCIAS}

BRASIL. Ministério da Educação. Diretrizes nacionais para a Educação Especial na Educação Básica. Secretaria de Educação Especial. MEC. SEESP, 2001. 79p.

BRASIL. Decreto $n^{\circ} 186$, de 2008. Congresso Nacional. Aprova o texto da Convenção sobre os Direitos das Pessoas com Deficiência e de seu Protocolo Facultativo, assinados em Nova Iorque, em 30 de março de 2007, Brasília, DF, 2008.

BRASIL. Ministério da Educação e Cultura. Secretaria de Educação Especial (SEESP). Política nacional de educação especial na perspectiva da educação inclusiva. Brasília: MEC, 2008b.

\begin{tabular}{l|c|c|c|c|c|c|} 
(C) Rev. Educ. Perspec. & Viçosa, $M G$ & v.9 & n.1 & p.127-141 & jan./abr. 2018 & eISSN 2178-8359 \\
\hline
\end{tabular}


BRASIL. Resolução no 4, de 2 de outubro de 2009. Brasília: MEC/CNE/CEB. 2009.

BRASIL. Decreto $n^{\circ} 7.611$, de 17 de novembro de 2011. Dispõe sobre a educação especial, o atendimento educacional especializado e dá outras providências. Presidência da República. Casa Civil. 2011. Disponível em:

<http://www.planalto.gov.br/ccivil_03/_ato2011-2014/2011/decreto/d7611.htm> Acesso em: 07 set. 2017.

BRAUN, Patricia. Análise quase-experimental do efeito de um programa instrucional sobre autocontrole para professores da educação infantil e do ensino fundamental. 2004. Dissertação (Mestrado em Educação) - Universidade do Estado do Rio de Janeiro, Rio de Janeiro, RJ, 2004.

CORREIA, Luís Miranda. Alunos com necessidades educativas especiais nas classes regulares. Coleção Educação Especial. Porto: Porto Editora, 1997.

CRUZ, Mara Lúcia Reis Monteiro; et al. Plano de Desenvolvimento Psicoeducacional Individualizado: percurso inicial para elaboração e aplicação. In: Anais do Seminário Internacional - as Redes educativas e as tecnologias: práticas/teorias sociais na contemporaneidade. FE/UERJ, Rio de Janeiro, 6-9 jun. 2011.

DECLARAÇÃo DE SALAMANCA. Sobre Princípios, Políticas e Práticas na Área das Necessidades Educativas Especiais. 1994. Disponível em:

<http://portal.mec.gov.br/seesp/arquivos/pdf/salamanca.pdf>. Acesso em: 10 set. 2017.

GALLAHUE, David; DONNELLY, Frances Cleland. Educação Física desenvolvimentista para todas as crianças. 4. ed. São Paulo: Phorte, 2008.

GLAT, Rosana; et al. Plano educacional individualizado: uma estratégia a ser construída no processo de formação docente. Ciências Humanas e Sociais em Revista, v. 34, n. 1, p. 79$100,2012$.

GLAT, Rosana; PLETSCH, Márcia Denise. Plano Educacional Individualizado (PEI): um diálogo entre práticas curriculares e processos de avaliação escolar. In: GLAT, Rosana; PLETSCH, Márcia Denise (Orgs.). Estratégias educacionais diferenciadas para alunos com necessidades especiais. 1. ed. Rio de Janeiro/RJ: EDUERJ, v. 1, p. 17-32, 2013.

JESUS, Denise Meyrelles de. Inclusão Escolar, Formação Continuada e Pesquisa-ação Colaborativa. In: BAPTISTA, Cláudio Roberto (Org.). Inclusão e escolarização: Múltiplas perspectivas. Porto Alegre: Mediação, p. 95-106, 2006.

KEMPINSKI, Igor Vinícius.; et al. Plano Educacional Individualizado: uma proposta de Intervenção. Revista da Sobama, Marília, v. 16, n. 1, p. 23-32, jan./jun. 2015.

LOVISOLO, Hugo. Educação Física: a arte da mediação. Rio de Janeiro: Sprint, 1995.

\begin{tabular}{l|c|c|c|c|c|c} 
(C) Rev. Educ. Perspec. & Viçosa, $M G$ & v.9 & n.1 & p.127-141 & jan./abr. 2018 & eISSN 2178-8359 \\
\hline
\end{tabular}


MARTÍN, Elena; SOLÉ, Isabel. Orientación educativa. Modelos y estratégias de intervención. Barcelona: GRAÓ, 2011.

MARTINI, Maiara Calomeno. Repensando a avaliação Psicopedagógica. In: MÄDER, Bruno Jardini (Org.). Psicologia escolar/educacional: ações e debates em psicologia escolar/educacional. Curitiba, CRP-PR, p. 51-57, 2016.

MAZZOTTA, Marcos José Silveira. Educação Especial no Brasil: história e políticas públicas. São Paulo: Editora Cortez, 2005.

MENDES, Enicéia Gonçalves. Breve histórico da Educação Especial no Brasil. Revista Educación y Pedagogía, v. 22, n. 57, mayo/ago. 2010. Disponível em:

$<$ http://aprendeenlinea.udea.edu.co/revistas/index.php/revistaeyp/article/view/9842/9041>. Acesso em: 08 set. 2017.

MUNSTER, Mey de Abreu van; et al. Plano de Ensino Individualizado Aplicado à Educação Física: Validação de Inventário na Versão em Português. Revista da Sobama, Marília, v. 15, n. 1, p. 43-54, 2014.

NASCIMENTO, Hérica Aguiar do. O plano educacional individualizado e o currículo funcional natural como estratégias para favorecer o aprendizado de alunos com deficiência intelectual. Monografia (Graduação em Pedagogia). Faculdade de Educação, Universidade do Estado do Rio de Janeiro, Rio de Janeiro, 2011.

PACHECO, José Francisco; et al. Caminhos para a inclusão: um guia para o aprimoramento da equipe escolar. Porto Alegre: ARTMED, 2007.

PLETSCH, Márcia Denise. Repensando a inclusão escolar: diretrizes políticas, práticas curriculares e deficiência intelectual. Editoras NAU \& EDUR, Rio de Janeiro, 2010.

PLETSCH, Márcia Denise; GLAT, Rosana. Pesquisa-ação: estratégia de formação continuada para favorecer a inclusão escolar. Revista Espaço do INES, n. 33, Rio de Janeiro, 2010. Disponível em: <http://www.eduinclusivapesquerj.pro.br/images/pdf/PLETSCH_GLAT_Artigosemperiodicos_2010.pdf >. Acesso em: 05 set. 2017.

PLETSCH, Márcia Denise; GLAT, Rosana. A escolarização de alunos com deficiência intelectual: uma análise da aplicação do Plano de Desenvolvimento Educacional Individualizado. Linhas Críticas, Brasília, DF, v. 18, n. 35, p. 193-208, 2012.

PORTUGAL. Reorientação das escolas especiais em centros de recursos: documento estratégico. Ministério da Educação: Portugal, 2006.

PORTUGAL. Decreto-lei $n^{\circ} 3$, de 11 de janeiro de 2008. Define os apoios especializados a prestar na educação pré-escolar e nos ensinos básico e secundário dos sectores público, particular e cooperativo. Ministério da Educação. Diário da República, $1^{a}$ série, n. 4, 7 de

\begin{tabular}{l|l|l|l|l|l|l} 
(C) Rev. Educ. Perspec. & Viçosa, $M G$ & v.9 & n.1 & p.127-141 & jan./abr. 2018 & eISSN 2178-8359 \\
\hline
\end{tabular}


janeiro, 2008. Disponível em:

<http://www.dge.mec.pt/sites/default/files/EInfancia/documentos/0015400164.pdf> Acesso em: 04 set. 2017.

SMITH, Débora Deustch. Introdução à Educação Especial: ensinar em tempos de inclusão. 5. ed. Porto Alegre: ARTMED, 2008.

SOUZA, Calixto Júnior de. Entre o adaptar e o incluir: uma abordagem interdisciplinar da disciplina de educação física adaptada. Revista da Sobama, Marília, v. 15, n. 1, p. 31-34, 2014.

TARTUCI, Dulcéria; et al. Avaliação e o Atendimento Educacional Especializado. Poíesis Pedagógica, Catalão - GO, v. 12, n. 1, p. 67-93, jan./jun. 2014. Disponível em:

<https://www.revistas.ufg.br/poiesis/article/viewFile/31207/16805>. Acesso em: 10 set. 2017.

THERRIEN, Jacques. O saber social da prática docente. Educação e sociedade, n. 46, p. 408-418, dez. 1993.

THIOLLENT, Michel. Metodologia da Pesquisa-ação. São Paulo: Cortez, 1988.

VIANNA, Márcia Marin; et al. Plano Educacional Individualizado - Que ferramenta é esta? Trabalho apresentado no VII Encontro da Associação Brasileira de Pesquisadores em Educação Especial, UEL, Londrina, 2011.

VYGOTSKI, Lev Semionovitch. Obras Escogidas: Fundamentos de la Defectologia, T. 5. Visor DIS. S.A.: Madrid, 1997.

YOUNG, Michael. Teoria do currículo: o que é e porque é importante? Cadernos de Pesquisa, v. 44, n. 151, p. 190-202, mar. 2014.

ZEICHNER, Kenneth M. O professor como prático reflexivo. In: ZEICHNER, Kenneth M. (Org.). A formação reflexiva de professores: ideias e práticas. Lisboa: Educa, p. 13-28, 1993. 


\section{SOBRE OS AUTORES}

${ }^{1}$ Letícia Aparecida Alves de Lima: Oficial do Magistério Militar na área de Língua Portuguesa. Especialista em Educação Especial. Professora, Assessora Pedagógica e Membro da Seção de Atendimento Educacional Especializado no Colégio Militar de Curitiba. E-mail: letslima26@hotmail.com - ORCID: http://orcid.org/0000-0002-8439-3029

${ }^{2}$ Ana Eliza Gonçalves Ferreira: Doutorado em Engenharia Mecânica pela Universidade Federal do Paraná (UFPR). Mestre em Matemática pela Universidade Estadual de Ponta Grossa (UEPG). Licenciada em Matemática. Professora do Ensino Básico, Técnico e Tecnológico no Colégio Militar de Curitiba. E-mail: anaeliza_gf@ hotmail.com - ORCID: http://orcid.org/0000-0002-1485-4600

${ }^{3}$ Marcus Vinicius Gonçalves da Silva: Doutorando em Gestão Urbana pela Pontifícia Universidade Católica do Paraná (PUCPR). E-mail: marvin.gsilva@gmail.com - ORCID: http://orcid.org/0000$\underline{0003-2145-0871}$ 